\title{
Learning online
}

E-learning and the domestic market in the UK

\author{
Margaret Scanlon and David Buckingham \\ Institute of Education, University of London, 20 Bedford Way, London WC1H OAL; \\ m.scanlon@ioe.ac.uk;d.buckingham@ioe.ac.uk
}

\begin{abstract}
Over the past decade the Internet has become a vital educational resource. In this paper we look at the growing e-learning industry, focusing on the conflict of interests which has emerged between the public and private sectors. We also look at the impact of new media on the demand for more traditional media.
\end{abstract}

Key words: sites of learning, policy

\section{INTRODUCTION}

In the past decade, the home has become an increasingly important educational site. The British government's evangelistic emphasis on education now extends well beyond its efforts to raise "standards" in schools. Funding is currently available for a whole range of new initiatives that seek to extend the reach of schooling into children's leisure time. The steady extension of national testing has created an atmosphere of growing competition, not only between schools but also among parents and children. Education, it would seem, is the work of childhood, and it cannot be allowed to stop once children walk out of the classroom door.

Commercial companies have not been slow to grasp those opportunities. Parents are under increasing pressure to "invest" in their children's education by providing additional resources at home, most computer manufacturers claiming they can "help" your child to get ahead in the educational race (Nixon 1998; Buckingham, Scanlon and Sefton-Green 2001). Currently sales of educational materials designed for domestic use, for example, in the form of study guides and early learning materials, are booming. Private home tutoring is becoming more common and there has 
been a marked increase in the commercial provision of supplementary classes, not just in "extras" such as the arts but also in "basics" such as maths and literacy. The marketing of such goods and services often seeks to appeal to parents" "better nature" - their sense of what they should be doing in order to qualify as Good Parents.

On one level, commercial involvement in out-of-school learning is nothing new. There is a long history of parents providing educational resources at home. Luke (1989) and others have pointed out that the modern "invention" of childhood was accompanied by a whole range of pedagogic initiatives aimed at parents and children, including primers, advice manuals and instructional books and playthings. However the nature and scale of the operation have significantly changed in recent years. Technological developments, government policy and market forces have combined to bring about those changes.

The Internet shows the greatest potential for extending learning into the home. The number of homes with computers and Internet access has increased steadily over the last few years, thus increasing the potential for electronic learning. In this paper, which is drawn from an ongoing research project, we consider the current state of the e-learning industry, the growing market for educational web sites and the impact on the market for more traditional media. Our work is based on an analysis of the educational publishing industry, drawing on the trade press, market research reports and interviews with publishers and software/web site producers.

\section{THE INTERNET AND HOME LEARNING}

New media play an increasingly important role in education, both at home and in schools. Enthusiasts argue that computers have the potential to engage and motivate pupils in ways that conventional classroom teaching does not. Children are assumed to have a natural aptitude and enthusiasm for computers (whereas adults do not); and computers are seen to make learning automatically more interesting and exciting. In one of the more effusive treatises on this subject, Seymour Papert (1996) describes the "passionate love affair" between children and computers. On a more pragmatic level, familiarity with computers is now seen as important for the future of the "eeconomy". Partly for those reasons, the Department for Education and Science (DfES) is committed to connecting all schools to the Internet and email by the end of 2002. The Institute for Public Policy Research has recommended that they go further and ensure universal Internet access for everyone from the home (Tambini 2000). 
One key aspect of new media is their potential to extend the reach of schooling beyond the classroom. Computers are helping to break down some of the traditional barriers in terms of age and location: Education is no longer seen merely as something that takes place in a school/college/university between the ages of 5 and 21 (or beyond). Many commentators are predicting that in the future the home will become a more important site for education because children will be accessing information and classes via the Internet (Loveless and Ellis 2001). Michael Hargreaves, Chief Executive of the Qualifications and Curriculum Authority (QCA), predicted that "quite soon we shall see sixth formers spending up to half their time out of school, undertaking learning at home and in other places" (Buckingham and McFarlane 2001).

\subsection{Concerns about e-learning}

Despite the optimism and utopian rhetoric that often surrounds discussions about new media and education, a number of concerns have also been raised. The so-called digital divide between those who have access to home computers and those who do not has been well documented (BECTa 2001).

Even in cases where children do have access to a computer, such access does not automatically mean that it will be used for educational purposes. Differential access to the Internet at home may also be influenced by parental attitudes towards the Internet and by the cultural resources that a family can bring to bear (Furlong, et al. 2000). Another important use is whether ICT is capable of making any real difference to education and whether there has been a sufficient return on the huge investment made. A report published by the US-based Alliance for Childhood argues that there is no clear evidence that primary school children have made any gains as a result of technology use (Coughlan 2001). The report also asks what advances might have been achieved if similar amounts of money had been pumped into smaller class sizes, more teachers, more books or better school buildings. Despite the concerns, the number of homes with computers and Internet access continues to rise steadily. Computers have been heavily marketed as an educational resource and lack of access to the Internet at home is now seen as a serious disadvantage in educational terms (Nixon 1998). 


\section{OLD AND NEW MEDIA}

One indicator of the growing importance of the Internet in home education is the effect that it has had on the market for print media and software. Competition from the Internet has led to a decline in demand for glossy reference books, especially encyclopaedias and atlases. Problems for publishers in that sector started several years ago when CD-ROMs were first developed and computer companies decided to include reference packages such as Encarta with their computers. Now encyclopaedias are available free on the Internet and there are hundreds of sites linked to museums, libraries, art galleries, etc. in direct competition with the reference book market.

The Internet also has a number of advantages over print in terms of providing more powerful search tools and hyperlinks with related sites. It invariably influences what publishers decide to produce and how they produce it. Some are reluctant to publish encyclopaedias and atlases since those can be updated on the Internet. Publishers are also wary of subjects such as geography, where content can be broken down into "sound bites" suitable for web sites. They try not to replicate information that is already on the Internet or look for different ways of approaching a subject. It is also evident that digital media are influencing the visual style of print texts and the ways in which they structure the reader's access to information. For example, a representative of one of the main reference publishers in the UK told us they were planning to use more computer graphics in their books because children are so familiar with those types of images. The idea is to make the transition from computer screens to books seem less great.

The market for CD-ROMs has also been affected. According to representatives of the main software producers, the market has started to slow down over the last few years, largely due to competition from the Internet. In the UK, concerns have even been raised about the future of school broadcasting. According to Robin Moss, former head of educational broadcasting at the Independent Television Commission, the BBC's school broadcasting service is being under-funded and undermined in the drive to create electronic learning resources (Brown 2002), a claim which the BBC vehemently denies (Stevenson 2002).

Despite competition from the Internet, reference publishers and software companies are not facing imminent ruin. Books still have many advantages over digital media. They are portable, easily accessible and, according to publishers, have greater authority because they have been through an editorial process. Furthermore, some parents are wary about letting their children use the Internet or may not have access to the Internet for economic reasons, although, by the same token, those parents may also be unable to 
afford books or software. Nevertheless, the advantages of CD-ROMs as compared to the Internet are increasingly difficult to identify.

The most obvious strategy for publishers and software companies is to find ways of using the Internet to their own advantage. Some are developing their own sites or becoming content providers for others, effectively using the Internet as another means of distributing content. Others are building connections between books or CD-ROMs and dedicated web sites to which purchasers will have restricted access. Overall, publishers seem to be rethinking their role and re-inventing themselves as information providers across different media. This is undoubtedly a testing time for publishers as they enter the unpredictable e-learning market.

\section{THE E-LEARNING INDUSTRY}

The e-learning industry is only just beginning to take shape, with many different players jostling for position in a very competitive market. A few of the companies involved have a public service obligation to offer educational content, the BBC and Channel 4 for example. Others are commercial companies, often with a stake in other media and/or education, for example the Times Educational Supplement (TES) and The Guardian. Software companies are especially interested in the possibilities of the Internet because of the decline in the CD-ROM market. Companies such as Europress and The Learning Company are now planning to develop their own web sites or become content providers for others. Apart from those commercial providers, non-profit organisations, schools and individuals are also creating educational web sites.

Although, in theory, anyone with access to the Internet can create a web site, there can be little doubt that established content providers in other media are particularly well favoured. Concerns about quality control on the Internet mean that companies with an established brand in other areas of the media or education, the BBC for example, have a distinct advantage if they develop web sites. Multimedia conglomerates such as Pearson or Vivendi are also in an ideal position to create educational sites because they already have access to content through their ownership of publishing and software companies. When the educational web site <education.com> was created in 2001 , it was able to draw on a number of properties owned by its parent company, Vivendi. Thus, according to information on the web site, <education.com> offers rich and varied content from major print publishers: Chambers-Harrap, Kingfisher, Larousse, Retz; and multimedia publishers: Coktel and its famous characters Adi and Adiboo, Knowledge Adventure and its Jump Ahead and Blaster Rangers. Similarly, Pearson is able to use 
content from its publishing subsidiaries Penguin and Dorling Kindersley in its online education material. In this respect, technological changes reinforce the tendency of changing patterns of ownership to create a more centralised industry. There has been a convergence of media, with companies like Granada having a stake in publishing, TV, software and, now, e-learning.

But e-learning and e-publishing are still in the developmental stage and one of the main issues facing commercial companies is how to make a return on their investment. The basic means of funding (or generating profit) is still uncertain. Subscriptions and advertising are two of the leading possibilities. Spark Learning, for example, has developed an elaborate system for generating income based on advertising, subscription fees from parents and schools, and sponsorship from London Electricity. In addition, the site has links to WH Smith and other retailers. There are also examples of companies developing sites which effectively have to be used in conjunction with other media, either print or digital. So, for example, Pearson have launched a study guides package comprising online testing and resources which can be accessed only by students who have purchased the book. Meanwhile, software producers are developing CD-ROMs that allow users to download additional content from the Internet.

While selling advertising space is common practice, some companies have taken a step further by setting up education web sites which essentially promote their own products or services. The Cadbury site is one example of how education, entertainment and advertising have been combined. Launched in 2000, the Cadbury Learning Zone is a free site aimed at the home and school, and purports to make learning "fun". There are three subject areas - maths, history and the environment - and separate information sections for parents and teachers. It is to be expected that the Cadbury brand name would be featured prominently, but most of the learning activities are based on a chocolate theme or linked to Cadbury. The maths section, for example, features "Mr. Cadbury's Chocolate Factory" and the characters are all named after chocolate products ("Buttons", "Fudge", "Curly Wurly" and "Chomp").

The history section focuses on the history of Cadbury. Only the environment part of the site does not focus specifically on chocolate and Cadbury, but the characters ("Yowies") feature in Cadbury products. The rationale behind setting learning activities in a "chocolate factory" is explained as follows: "Using as a focus the realistic context of maths in chocolate making, children will be able to gain an appreciation of the value of maths in a real working situation." Elsewhere the producers state that the Learning Zone is part of Cadbury's wider commitment to education, both within "our own communities" and at a national level. A more cynical view might be that the site provides a good deal of covert advertising for Cadbury. 
Interestingly, the Cadbury Learning Zone is a National Grid for Learning-approved site and is affiliated with Gridclub, the Bafta-winning DfES/Channel 4 site. In that context it is not surprising that the NGfL portal has in the past been criticised for its lack of substantive content: Comparisons have been made between the site and New Labour's other flagship project, the ill-fated Millennium Dome.

Apart from the business models outlined above, another important source of funding is through the government. Government policy in the last five years has done much to create the potential for an e-learning industry. As part of the NGfL initiative it has spent approximately $£ 1$ bn equipping schools with computers, training teachers and developing the NGfL portal. Commercial companies played an important part in the rollout of the NGfL and they clearly intend to be involved in the development of digital content for homes and schools. However, the emerging industry has from the start been characterised by a certain amount of tension between public and private sectors, which reflects broader developments in the "marketisation" of education (Gewirtz, Ball and Bowe 1995). The current debate over plans to create a digital curriculum brought these tensions to the forefront. As the government's plans for the provision of digital content became more ambitious they also became more contentious as commercial companies saw them as encroaching on their territory.

\section{THE DIGITAL CURRICULUM}

By 2001 the NGfL was one of the largest educational portals in Europe but, as noted above, it lacked substantial content. For commercial providers, this represented an enormous opportunity. Clearly the government was going to continue to play a significant role, but there were differences of opinion over what that role should be.

Much of the debate about government involvement has centred around the issue of whether it should foster a supply- or demand-led market for elearning. In the supply-led (or "top-down") model, the government would commission companies to produce content that would be free to users. Alternatively, it could authorise a state-subsidised organisation (in this case the BBC) to produce content. The demand-led model would involve funding being made available directly to users so that they could select and pay for the sites they want, which in turn would stimulate content production. The essence of this view is that the market will inevitably provide. Not surprisingly, commercial companies generally prefer the latter option, whilst the $\mathrm{BBC}$ has campaigned persistently for the former. The fundamental 
opposition has been at the heart of an ongoing debate about the development of digital content for schools and homes.

Some of the DfES's early initiatives have been generally well received. GridClub is a free online service provided by Channel 4 in the UK in partnership with Intuitive Media and Oracle, and funded by $£ 6$ million from the DfES. Designed to be used by children at home or at school, GridClub received good reviews in the press and has won a number of awards, though take-up has not been as high as expected. The DfES also funded a $£ 5$ million pilot project to develop courses in maths, Latin and Japanese at Key Stage 3. Content was developed by Granada Learning, the BBC and RM, and press reports suggest that the pilots were a success (Cole 2002). However, the initiatives were soon to be overshadowed by the controversy surrounding the BBC's plans for a digital curriculum.

In 2000 the BBC issued a consultation document outlining proposals to provide national curriculum learning materials free to users over the Internet and through digital TV. The project was to be funded through the license fee and would target both the school and the home market. The BBC justified its plans in terms of its track record in providing learning materials and its public service obligation to support education. Not surprisingly, the plans met with opposition from the commercial sector. In their view, allowing a state-subsidised body to spend up to $£ 150 \mathrm{~m}$ of license fees on developing digital content was tantamount to creating a public monopoly. Commercial companies argued that the planned digital curriculum was anti-competitive and would effectively exclude them from the growing digital education market. Like previous episodes in the development of the NGfL, the industry's views were often couched in altruistic or utopian terms, concerning "choice for schools", "quality" and teachers becoming "the longterm losers" if the free market is not allowed to prevail (Selwyn 1999).

Commercial companies got the opportunity to voice their objections when the DfES set up its own consultation process in 2001. In addition, industry lobbied MPs and their views were published in the press and at public meetings. Questions were even asked in parliament. Interestingly, the views of schools, parents, and organisations such as the Parents Information Network were almost never reported in the press. Some of the most strident criticism of the BBC's plans came from Merlin John, editor of the TES Online, who regularly castigated the $\mathrm{BBC}$ 's role, at one point describing the corporation as a "self-seeking organisation" which had "stumped up some cash in a back-room deal" (John 2001).

The suspicions and fears of the industry were further aroused in 2001 when the DfES awarded Granada and the BBC a $£ 42$ million contract to develop content for six General Certificate of Secondary Education (GCSE) subjects. Many companies object to such supply-led funding in principle, 
preferring direct funding to users, but the contract was also contentious because of the way in which it was awarded. The industry claimed that the terms of the original tender were changed: The tender appeared to discourage bids from non-TV companies, but it later transpired that most services were to be delivered online, not by television.

The debate rumbled on until the end of 2001 when a temporary compromise was reached. The government announced its plans for a "Curriculum Online" initiative whereby schools will receive $£ 50$ million in the form of "e-learning credits" to buy digital material. A content advisory panel will oversee the resources on offer, which will be available to homes as well as schools. At the same time the government announced that it would not be going ahead with the $£ 42 \mathrm{~m}$ award to Granada and the BBC. The secretary of state for education explained that the rapid development of technologies and the wider scope of Curriculum Online meant that the Department would not be proceeding with the initiative. However it appears that the $\mathrm{BBC}$ will go ahead with its plans for a digital curriculum, subject to approval by the Department for Culture, Media and Sport.

The Curriculum Online initiative seems to illustrate the increasing influence of the commercial sector in education and the conflicts of interest that can arise between public and private spheres. New Labour has from the start fostered commercial involvement in initiatives such as the NGfL but business interests will inevitably resist government interventions that appear to threaten their profitability. As Selwyn and Fitz (2001) have pointed out, handling the role of the private sector in what is very public policy is always going to be potentially problematic. In the debate over the provision of a digital curriculum the situation was made even more complicated by the involvement of the BBC. The dispute between the corporation and the commercial sector has not yet been resolved. In May 2000 a coalition of software firms were demanding a judicial review of the BBC's plans to spend $£ 150 \mathrm{~m}$ of licence money on developing the digital curriculum (Cassy 2002).

\section{CONCLUSION}

The rapid growth of educational web sites raises several questions that have a broader relevance to the contemporary study of education. The questions could be seen in terms of a set of changing relationships: Between the home and the school, between education and entertainment, and between the public and the private spheres. How the e-learning market "settles down" as it moves beyond the pioneering stage may well reveal a great deal about 
the future shape of educational markets and about the role the media are coming to play within them.

The home has become an increasingly important site for education, and initiatives such as the DfES's Curriculum Online and the BBC's digital curriculum have the potential to contribute to the trend. One of the clearly stated objectives of both initiatives is that they will provide content for schools and homes, and it is to be hoped that providers will distinguish between and cater for the needs of both groups. But there is a danger that the online education market will be dominated by provision for schools which is larger and more stable. As a result the material that is available to the home market may reflect a relatively narrow conception of learning. Already some of the main out-of-school learning sites are geared towards homework and revision, for example, Bitesize, revisewise, SOS Teacher and Homework High. The reality of electronic learning may be less exciting than the utopian scenarios described by Seymour Papert and others. Whilst revision and homework sites are no doubt useful, they are unlikely to engender "a passionate love affair" between children and computers.

However, it is too early to conclude that the domestic market for elearning will be driven by exams and national curriculum objectives, partly because different companies work on the basis of different business models. Some non-fiction publishers, for example, are producing materials that are specifically not geared towards the curriculum of one country so that they can reach an international audience. Meanwhile museums, art galleries, libraries and voluntary organisations in the UK and elsewhere are starting to provide spaces on their web sites which are designed for children. It may be through these routes that children find alternative learning resources.

Of course, for those who do not have access to the Internet at home such options are not easily available. Indeed the public debate over the digital curriculum and who should provide it largely ignored the fact that many families do not have Internet access and that not all schools have the broadband connections necessary to take advantage of the new resources. Therefore, in the short-term at least, the initiatives are likely to perpetuate existing inequalities both between homes and also between schools.

\section{REFERENCES}

BECTa (2001) The "Digital Divide": A Discussion Paper. Coventry: BECTA.

Brown, M. (2002) Switched off. The Guardian 14 May.

Buckingham, D. and McFarlane, A. (2001) A Digitally Driven Curriculum? London: The Institute for Public Policy Research. 
Buckingham, D., Scanlon, M. and Sefton-Green, J. (2001) Selling the digital dream: Marketing educational technology to teachers and parents. In A. Loveless and V. Ellis (eds.) ICT, Pedagogy and the Curriculum: Subject to Change. London: Routledge.

Cassy, J. (2002) Rivals threaten $\mathrm{BBC}$ with court for $£ 150 \mathrm{~m}$ online learning push. The Guardian $24^{\text {th }}$ May.

Cole, G. (2002) The digital dilemma. The Guardian $8^{\text {th }}$ January 2002.

Coughlan, S. (2001) Devil's advocate. Times Educational Supplement: Online $11^{\text {th }}$ May.

Furlong, J., Furlong, R., Facer, K. and Sutherland, R. (2000) The National Grid for Learning: A curriculum without walls. Cambridge Journal of Education 30 191-110.

Gewirtz, S., Ball, S. and Bowe, R. (1995) Markets, Choice and Equity in Education. Buckingham: Open University Press.

John, M. (2001) Lifelong learning: Until 6 pm. Times Educational Supplement Online $9^{\text {th }}$ November.

Loveless, A. and Ellis, V. (2001) ICT, Pedagogy and the Curriculum: Subject to Change. London: Routledge.

Luke, C. (1989) Pedagogy, Printing and Protestantism: The Discourse on Childhood. Albany, NY: SUNY Press.

Nixon, H. (1998) Fun and games are serious business. In J. Sefton-Green (ed.) Digital Diversions: Youth Culture in the Age of Multimedia. London: UCL Press.

Papert, S. (1996) The Connected Family. Atlanta: Longstreet Press.

Selwyn, N. (1999) "Gilding the Grid": The marketing of the National Grid for Learning. British Journal of Sociology of Education 201 59-72.

Selwyn, N. and Fitz, J. (2001) The National Grid for Learning: A case study of new labour education policy-making. Journal of Education Policy 162 127-147.

Stevenson, M. (2002) Auntie knows best. The Guardian 21 May.

Tambini, D. (2000) Universal Internet Access. London: London School of Economics and Political Science.

\section{BIOGRAPHIES}

Margaret Scanlon is a Research Officer in the Centre for the Study of Children, Youth and Media at the Institute of Education, University of London. The project on which she is currently working looks at the production, characteristics and uses of educational web sites designed for use in the home.

David Buckingham is Professor of Education at the Institute of Education, where he directs the Centre for the Study of Children, Youth and Media. He has conducted several research projects on children's interactions with electronic media and on media education. 